\title{
A PESQUISA EM CIÊNCIAS SOCIAIS HOJE ${ }^{\mathrm{i}}$
}

\author{
Michel Messu \\ Université de Nantes \& PHILéPOL Université Paris Descartes (France) \\ Traduzido por Lindomar Wessler Boneti \\ Pontifícia Universidade Católica do Paraná
}

\begin{abstract}
Resumo
Em vinte anos, talvez um pouco mais, as condições da pesquisa em ciências sociais obtiveram grandes mudanças. Atualmente nos cobram não somente a produção mais regularmente dos resultados, mas de produzi-los em condições de obter reconhecimento no contexto de uma nova escala: o reconhecimento internacional. Estas mudanças da pesquisa têm implicações sobre os mecanismos de avaliação, de financiamento, da publicação dos resultados e também pela língua falada entre os pesquisadores.
\end{abstract}

Palavras-chave: reconhecimento internacional; mecanismos de avaliação; pesquisa em ciências sociais.

\section{La recherche en sciences sociales aujourd'hui.}

\section{Résumé}

En une vingtaine d'années, peut-être plus, les conditions de la recherche en sciences sociales ont bien changées. On nous demande non seulement de produire plus régulièrement des résultats, mais de le faire dans des conditions de reconnaissance qui se situent à une nouvelle échelle : la reconnaissance internationale. Ces changements de la recherche ont des implications pour des mécanismes de l'évaluation, de le financement, de la publication des résultats et aussi pour la langue parlée parmi les chercheurs.

Mots-clés: reconnaissance international; mécanismes de l'évaluation; recherché en sciences socials

\section{Introdução}

Em vinte anos, talvez um pouco mais, as condições de pesquisa em ciências sociais mudaram. Nos dias atuais exige-se não apenas produzir resultados mais regulares, mas fazer isto em condições de reconhecimento, enquadrando-se em uma nova escala: 0 reconhecimento internacional.

Por um longo tempo, de fato, pesquisas em ciências sociais foram concebidas, realizadas e avaliadas em nível nacional, com financiamento local e nacional. Suas avaliações eram feitas pelos nossos "pares", isto é, os nossos colegas de universidades nacionais, os mesmos que costumávamos encontrar nas nossas universidades, nos encontros científicos, os mesmos pertencentes a conselhos editoriais nas revistas em que publicávamos. Em outras palavras, estávamos entre nós, sabíamos que falávamos a mesma língua, compartilhando ou não os mesmos objetos de pesquisa ou as mesmas abordagens; tínhamos os mesmos quadros referenciais teóricos e os dados empíricos. Em suma, a concorrência, a emulação, 
apresentavam-se internamente entre as fronteiras de um país (ou de alguns países onde a língua comum nos une, por exemplo, entre a França, Bélgica, Suíça e Quebec).

Daí o surgimento de tradições, Escolas, especificidades enraizadas em lugares bem definidos, podendo ser caracterizadas geográfica e culturalmente. Assim, a Escola Alemã, a Escola Francesa, a Escola de Chicago, a sociologia, a tradição anglo-americana versus tradição francófona em antropologia, etc., são casos bem conhecidos que identificam esse fenômeno. Era sobre esta base que se desenvolviam as ciências sociais nacionais.

Mas isto tudo mudou.

\section{As grandes mudanças na pesquisa em ciências sociais}

Para iniciar, o que mudou : uma mudança que ocorreu igualmente no Brasil, na Europa, América do Norte e no resto do mundo, foi a internacionalização da pesquisa. A pesquisa se internacionalizou de muitas maneiras: através do desenvolvimento de comparações internacionais, organizações das redes internacionais de investigação, pelo financiamento internacional e pela publicação on-line - periódicos eletrônicos.

\section{Em relação à comparação}

Mais e mais pesquisas são suscetíveis de serem realizadas comparando as situações em diferentes países. O que foi excepcional na década de 1970 tornou-se regra na atualidade. O desemprego na França, por exemplo, não é possível de ser analisado se não for relacionado com o que ocorre na Espanha, Portugal, Alemanha, em todos os países da Europa, ou seja, do mundo ocidental. Sobre o plano econômico, o PIB (GDP) e suas várias versões (PIB PPP: paridade de poder aquisitivo, etc.) tornou-se um critério-chave para avaliar, não importa a situação, se nacional, regional ou local. Ao avaliar a "pobreza" no Brasil está se fazendo comparações com o resto da América Latina ou do mundo. A mesma coisa ocorre em relação aos sistemas de protecção social, educação, saúde, meio ambiente, etc. Em outras palavras, a nossa visão de questões sociais é feita primeiramente tomando como referência a sua posição no mundo. Isto se apresenta, portanto, menos como questões "em si", cujo tratamento poderia legitimamente ocorrer no âmbito nacional, circunscrevendo sua relevância.

Existem boas razões epistemológicas e metodológicas para assim se proceder. $\mathrm{Na}$ verdade, muitos fenômenos sociais serão daqui para frente apresentados como os efeitos de fenômenos globais ou como singularidades nacionais de tratamento de problemas colocados a uma toda escala coletiva, assim como as respostas para as quais a modalidade ética é a possibilidade.

Portanto, a comparação das situações nacionais é exigida como condição para compreensão do fenômeno estudado. Assim dizendo, a abordagem comparativa evidencia problemas metodológicos. Portanto, compara-se o quê exatamente? Por outro lado, a comparação se legitima como uma nova maneira de dar sentido aos nossos objetos de pesquisa.

\section{Em relação à organização de redes de pesquisa:}

O que mudou também foi a organização prática da pesquisa, que cada vez mais é realizada no âmbito de redes internacionais. $\mathrm{O}$ « réseautage » como dizem os quebequenses, $\mathrm{O}$ "Networking", como dizem os anglófonos, a criação de redes de investigadores, seus objetos de pesquisa e seus resultados, mas também de suas questões teóricas, metodológicas, dos seus dados empíricos, de suas informações bibliográficas, etc., tornou-se uma atividade cotidiana do pesquisador. A pesquisa está longe de ser um exercício solitário. Ela exige comunicação e 
intercâmbio com inúmeros pesquisadores ao redor do mundo, e não apenas com os da equipe do seu centro de pesquisas.

Eu, por exemplo, sou membro de uma rede Linkedin de discussão intitulada "Research, Methodology and Statistics in the Social Sciences" e não há dia que não se abrem 2, 3, 4 pedidos de discussões sobre um problema com um ou outro pesquisador dentre os membros. São pesquisadores localizados tanto nos Estados Unidos, China, África, Índia e Brasil, pertencentes a diferentes universidades e outras organizações de pesquisa. Eles podem ser jovens pesquisadores ou professores titulares com vasta experiência. Mas eles compartilham um problema comum e o discutem diretamente.

Isto significa dizer que algumas pesquisas hoje escapam das estruturas hierárquicas da organização local e nacional. Esta pesquisa se realiza também através da Internet, em comum acordo entre pesquisadores de todas as origens, o que pode ser entendido como um ganho de liberdade do investigador.

Mas para além dessas práticas individuais de trabalho em rede, está surgindo, cada vez mais, um constrangimento institucional criado pela obrigação da colaboração internacional. Nossas instituições nacionais exigem dos seus pesquisadores a multiplicação de atividades colaborativas com equipes de outros países e de outros centros de pesquisa. Embora as atividades de pesquisa de hoje se realizem entre membros de centros implantados em vários países, estas se realizam por vezes para efeito de comparação, porém nem sempre. Isso permite que as questões comuns sejam elaboradas e testadas, desta forma, com resultados que suplantam as fronteiras nacionais e se difundem de forma mais ampla. Assim, em termos de desenvolvimento econômico e social, essas são problemáticas compartilhadas, muitas vezes usadas por organizações internacionais (FMI, Banco Mundial, UNESCO, etc.), cujos objetos têm origem no mesmo projeto de pesquisa da equipe local. Eles coletam dados locais comparando-os com os de outras equipes e uniformizando assim a abordagem da problemática. O Conselho Latinoamericano de Ciências Sociais (CLACSO) bem conhecido aqui no Brasil, também tem esse papel. Para nós franceses, são os programas europeus que o desempenham.

Ainda há a considerar a existência de instâncias nacionais ou locais de pesquisa, mas estas, cada vez mais, exigem que seus projetos investigativos sejam inseridos no âmbito de programas internacionais. Essas instâncias (de pesquisas) adotam o procedimento de apoiar as primeiras iniciativas dos centros de investigação, de modo que essas iniciativas integrem as redes internacionais.

\section{Em relação ao financiamento internacional:}

$\mathrm{Na}$ maioria das vezes, as questões mutáveis de tais políticas são as financeiras. $\mathrm{Na}$ verdade, os recursos alocados para a pesquisa estão de agora em diante, concentrados em poucos lugares: agências nacionais ou internacionais, organizações não governamentais ou ONGs poderosas, gerenciando, portanto, fundos públicos e/ou privados. De repente, as instâncias locais, especialmente as universitárias, se tornam menos presentes em programas importantes de investigação, mesmo que ainda aplicando seus próprios meios, mas à sua maneira.

Esta dependência em relação às fontes de financiamento internacional tem efeitos evidentes em termos de resultados e reconhecimento dos investigadores. Isso muitas vezes torna-se um critério para avaliá-los. Muitas vezes no contexto do tema ou dos projetos de investigação, é mencionado (e se é solicitado a mencionar) quanto custa em US, $\$$, em $€$ ou em outra moeda, um determinado pesquisador, traduzindo-se como prova de reconhecimento e credibilidade. Isso facilita a obtenção de um novo crédito e reforça a tendência ao que 
alguns chamam de imposição da problemática. De qualquer maneira, isso tende a reforçar estruturas de investigação predefinidas em instâncias internacionalizadas.

\section{1) Em relação à publicação on-line, especialmente às "revistas eletrônicas"}

Outro fator que torna a pesquisa mais e mais independente da estrutura nacional: a publicação dos resultados. Durante muito tempo isso se fez em revistas nacionais, por vezes, muito antigas (como no caso da França, revistas fundadas por Durkheim, Gurvitch, ou patrocinadas por grandes nomes como Aron, Lévi-Strauss, Touraine, Bourdieu... isto para a sociologia) nas quais a pesquisa era publicada e informava seus resultados a um público essencialmente nacional. $\mathrm{O}$ reconhecimento se fazia, portanto, através dessas publicações nacionais, o que se traduziria por utilizações de referências bibliografias essencialmente nacionais. A título de curiosidade, faziam-se consultas a revistas estrangeiras, mas estas não tinham o caráter de essencialidade como as revistas nacionais.

Mas era antes de tudo por meio de livros, que se fazia a divulgação e o reconhecimento da investigação. Em geral, quando a idade e a experiência ajudavam, uma proposta teórica original, uma análise inédita ou resultados incontestavelmente novos, poderiam ser propostos a uma editora com carimbo "universitária". O máximo do reconhecimento era a tradução do livro em outros idiomas além daquele no qual foi escrito. Assim acessava-se então à categoria dos happy few da pesquisa nacional.

Doravante, o reconhecimento se faz pela publicação de artigos, mas não em qualquer revista. A publicação, especialmente se o pesquisador é jovem, deve receber imediatamente o reconhecimento internacional e deve ser capaz de ser apresentada em algumas "grandes revistas". Nossas instâncias acadêmicas promovem também, às vezes, rankings dessas revistas. As primeiras são geralmente anglo-americanas. Quase todas são, seja exclusivamente, seja complementarmente "on-line", "revistas eletrônicas" acessíveis através da internet, por vezes, com os custos de acesso, às vezes com acesso gratuito.

Ainda apresenta-se uma espécie de mercado relacionado às revistas, algumas estão lá para ganhar dinheiro, e para isto procuram diariamente pesquisadores por e-mail, porque sabem da necessidade imperativa dos mesmos em publicarem. Assim se tem particularmente para jovens investigadores, uma espécie de comercialização de artigos de pesquisa, obrigando-os a aprofundarem suas pesquisas. Mas para outras revistas, estritamente acadêmicas, tendem a reforçar os seus critérios de aceitação, uma vez que elas recebem mais e mais propostas de artigos. Frequentemente adotam políticas, sejam de maior especialização, sejam, ao contrário, de maior diversificação.

Em suma, a forte pressão institucional para a publicação de artigos faz com que os pesquisadores sejam condicionados a publicarem amplamente em "revistas eletrônicas".

\section{2) Os benefícios dessas mudanças}

Múltiplas consequências estão associadas a essas mudanças. Algumas são mais benéficas para a pesquisa. Examinarei apenas três, as quais eu acho que são importantes e bastante vantajosas:

- Redução dos confinamentos teóricos.

Referindo-me à situação francesa, sem dúvida, foi a internacionalização da investigação que permitiu superar os conflitos de Escolas que marcaram e paralisaram um pouco as pesquisas a partir de 1970. Sem entrar em detalhes, a situação da pesquisa, particularmente em sociologia, mas também é verdadeiro em economia e em outras 
disciplinas, congelou as brigas de aparência teórica, mas mais fundamentalmente de opção ideológica. Querelas "chapelles" (igrejas), como se diz na França, mas dentro das quais os pesquisadores tinham que se apresentar para obter qualquer tipo de reconhecimento. Ser filiado a uma corrente de pensamento, esta era a regra, implícita, mas fortemente presente e obrigatória. Com isto, apresentavam-se as consequências em termos de financiamento, posições de pesquisa, publicação, dentre outras.

O desenvolvimento da internacionalização da investigação nos permitiu superar essas barreiras nacionais.

- Em segundo lugar, reduziu-se o "clientelismo" local. Ou seja, esses tipos de benefícios adquiridos ao longo do tempo que fizeram com que alguns centros de pesquisa, certas equipes, desfrutassem de uma vantagem natural pela convivência que tinham entre e com os agentes de decisões locais e de pesquisadores instalados no ambiente local. A suposta competição entre as equipes era, portanto, muitas vezes distorcida por esse sistema de convivência.

\section{- A internacionalização da investigação}

- Finalmente, a internacionalização teve muitos efeitos benéficos para a divulgação dos resultados da investigação. Mais uma vez, dependendo menos das redes locais ou redes constituídas ao redor de Escolas Teóricas, a difusão de resultados pode ser feita em uma escala muito maior. Ao abordar « urbi et orbi", o pesquisador pode ser reconhecido para além do círculo em que ele está localizado. Isto se dá com limites e, às vezes, com obstáculos. E aqui é necessário pensar, em particular, a língua através da qual predominantemente se faz essa transmissão. Mas esta questão eu prefiro tratar com mais detalhes na próxima seção sobre os inconvenientes da internacionalização da investigação nas ciências sociais.

\section{3) As desvantagens destas alterações}

Antes de tratar sobre a questão da língua, eu gostaria de sublinhar uma das que me parece a principal consequência das mudanças na forma de conceber e realizar pesquisas. Refiro-me à tendência de padronização da pesquisa. Esta padronização ocorre de diferentes maneiras:

- Pela imposição da problemática, tendo origem mais frequentemente, em órgãos financiadores da pesquisa. Eu já mencionei isso, mas eu diria que esta forma de imposição direta e imperativa, é realmente muito pouco frequente. Exceto, a professar opções teóricas às quais são discutidas, além de saber se as mesmas aparecem no âmbito da disciplina praticada ou se elas são realizadas apenas em suas margens. Mas, dentro do corpo teórico reconhecido das disciplinas das ciências sociais, a variedade de abordagens é geralmente aceita, mesmo porque os comitês de avaliação de projetos são compostos por representantes dessas disciplinas e pode haver entre eles, diferenças de opções teóricas. A padronização das questões de investigação não se faz, portanto, de maneira tão autoritária pela imposição de opções teóricas dos órgãos que controlam a pesquisa.

Mais contundente, no sentido da padronização, parece ser a imposição de abordagem metodológica e ética. Isto se dá muitas vezes, através do método a ser adotado que se realiza pela imposição da problemática. As ciências sociais admitem, em princípio, uma grande variedade de métodos e procedimentos de investigação. E o debate sobre o método comporta frequentemente um desafio de compreensão e de análise do objeto da pesquisa. A construção dos dados, das categorias de análise, dos procedimentos de análise de dados, dos conceitos utilizados para formular as conclusões, todo isso interfere plenamente, como se sabe, na 
produção dos resultados de pesquisa. No entanto, limitar os dados a um tipo (a estatística nacional, por exemplo) orientar os procedimentos de investigação na direção de uma mesma abordagem (como tipo de entrevista, configuração de quotas, etc.), realizar uma análise padrão desses dados (sejam estes quantitativos ou qualitativos), tudo isso tende a produzir modelos padronizados de pesquisa. Ou seja, são os procedimentos e regras da pesquisa que obedecem antes de tudo à construção, podendo assim ser capazes de discutir a sua relevância. A construção prévia do objeto, construção prévia de conceituais de definição do objeto, construção prévia metodológica de apreciação do objeto, etc., são pré-requisitos logicamente componentes da realização de pesquisas e devem permanecer como uma prerrogativa do pesquisador. Aceitar que isso é feito no conjunto da pesquisa é promover e reforçar a investigação padronizada. Com isso constata-se uma espécie de "formatação" de publicações.

Mais perigoso, parece-me, caminhando na mesma direção da padronização, é a chamada restrição ética. Esta é imposta pelos diversos Comitês de Ética os quais controlam os organismos de promoção de investigações. Esses Comitês têm como objetivo, ou pelo menos assim é proclamado, proteger as pessoas que são seres humanos objetos de pesquisa, ou seja, garantindo-lhes "direitos" para não serem maltratados pelos pesquisadores. A intenção é louvável, não se discute. Mas, mais frequentemente os "charters éticos" se apresentam para proteger suas instituições contra processos judiciais que poderiam ser movidos pelas pessoas objeto da pesquisa, insatisfeitas com o comportamento de pesquisadores ou com os resultados da investigação.

Mas, ainda mais, esses "charters éticos" tendem a excluir certos procedimentos ou certos métodos considerados demasiados intrusivos para o lugar de tais "sujeitos" e, portanto, por isso, ocorrendo proibições de certos tipos de pesquisa. O sociólogo Howard Becker, declarou que, se tivesse de seguir os "charters éticos" impostos pelas universidades americanas de hoje, ele nunca poderia ter escrito seus livros que todo mundo reconhece como grandes obras da disciplina Sociologia. A partir deste ponto de vista, a imposição dos "charters éticos" pelas organizações que comandam a pesquisa produz um real efeito de padronização, de uniformização e de empobrecimento da pesquisa. É um efeito altamente negativo das mudanças das investigações que estamos analisando.

Agora analisaremos a questão da língua, esta que cada vez mais comunica os resultados da pesquisa. Trata-se, bem entendido, da utilização predominante do Inglês. As grandes Revistas são todas, ou quase todas, de língua inglesa e se queremos nos informar rapidamente sobre notícias da nossa disciplina, melhor praticar o Inglês. Mas antes de falar sobre o imperialismo do idioma Inglês, gostaria de precisar duas coisas:

A primeira é que o Inglês é a língua utilizada nas trocas convencionais dentro de cada disciplina. Trata-se da língua Inglesa reduzida, por vezes, muito técnica e que é usada inicialmente como uma linguagem comum entre os pesquisadores praticantes de diferentes idiomas na vida cotidiana. Além disso, essa língua frequentemente provoca risos dos britânicos, "puro açúcar" como se diz na França, porque esse inglês lhes parece bastante incorreto. Até mesmo inventou-se uma palavra para dizer e designar o inglês praticado por pessoas não inglesas, apenas para indicar algumas questões referentes às suas próprias atividades, falamos de "globish" de "Inglês global". Muitas vezes, porém, trata-se de instâncias internacionais, como a da ciência política, que contamina a comunidade de pesquisa.

Mesmo assim, é com este Inglês que as trocas se realizam em escala mundial, entre pesquisadores de países muito diferentes os quais jamais trocaram informações sem que fosse nessa forma de usar o Inglês. Quem, na França ou no Brasil teria conhecimento do trabalho de um investigador paquistanês, da Indonésia, da África do Sul, da Letônia, etc., sem a utilização dessa linguagem comum de Inglês? Trata-se de uma língua comum, uma vez que, de fato, é a mais praticada no mundo para este tipo de intercâmbio. Inglês é, portanto o meio de 
comunicação entre os pesquisadores. Por outro lado, essa não é uma linguagem universal com a qual se realiza qualquer pesquisa.

De fato, dominar mais ou menos corretamente o Inglês não é o suficiente para fazer numerosas investigações. Particularmente nas ciências sociais, onde o material da pesquisa é um "material humano", definido histórica e culturalmente, a prática da língua nacional é, portanto, muitas vezes indispensável. Viu-se muito claramente na chamada "Primavera Árabe", quando eram os pesquisadores árabes que poderiam melhor explicar o que estava acontecendo. Aquelas pessoas que dominavam apenas o Inglês muitas vezes permaneceram na superfície das coisas. Outro exemplo, os atuais pesquisadores que se dedicam ao estudo sobre a China não conseguem entender grande coisa, além do discurso das autoridades, se elas não falam um pouco de mandarim ou de outros dialetos chineses. Isto significa que a pesquisa não pode ser realizada utilizando uma única linguagem, mesmo que esta seja comum para os pesquisadores. A pesquisa exige também que se tome em consideração a linguagem dos "sujeitos" que são objetos de investigação. Isto é, não se deve considerar apenas a linguagem utilizada entre os pesquisadores e pelos pesquisadores.

Mas é preciso considerar que deve haver uma linguagem comum que sirva de instrumento de troca entre pesquisadores. Então, este é o Inglês! Devo lhes dizer, isto provoca muita tristeza aos franceses, especialmente aquelas pessoas que pensavam que eram os únicos capazes, a partir do Século das Luzes, de "iluminar" o mundo.

\section{Um apelo por uma pesquisa multinacional não padronizada}

Para finalizar, eu gostaria de fazer uma proposta relacionada ao desenvolvimento da pesquisa em ciências sociais. Eu gostaria de pleitear pela manutenção de uma pesquisa multinacional não standard. As mudanças que observamos na pesquisa, das quais fiz considerações, comportam vantagens e desvantagens. Adotaremos as vantagens e combateremos as inconveniências.

Adotaremos o poder de sermos capazes de falar diretamente com outros pesquisadores para além das barreiras institucionais, Escolas de pensamento, circuitos fechados - locais ou nacionais - de financiamento. Assim a pesquisa poderia contar com menor base de relações pessoais, conveniências institucionais, de enfrentar circuitos fechados de reconhecimento, mas realizando uma pesquisa às vezes mais marcada pela busca do "espírito científico", em qualquer caso, mais facilmente heurística, mais centrada na compreensão do objeto de estudo.

Adotaremos o poder de comunicar amplamente nossos resultados, para além das divisões de Escolas, hábitos ou preferências teórico-ideológicas de Revistas e de editores. As Revistas se adaptarão e os editores farão. O "Cyber espaço" autoriza desde que o pesquisador aumente o seu estado de vigilância.

Mas adotaremos também o poder de conduzir a pesquisa de acordo com procedimentos reconhecidos pelas disciplinas, a pesquisa que nós queremos, e não apenas aquelas que são adequadas para as agências nacionais ou internacionais que as financiam. Adotaremos o poder de dizer "não" às imposições de métodos e abordagens, na medida em que nos parecer que estamos indo contra as descobertas científicas e a inovação heurística. Devemos confirmar que a ética se coloca do lado dos pesquisadores e não do lado das instituições gerenciadoras de pesquisa.

Proclamamos enfim, a nossa capacidade de encontrar, inventar, produzir resultados que podem renovar o conhecimento. Continuaremos, portanto fazendo o nosso trabalho de pesquisadores, no sentido pleno do termo, com os seus riscos, desconfortos, incertezas, mesmo que se deva fazer no âmbito das novas condições de pesquisa internacionalizada, sem 
porém nos tornarmos funcionários de uma pesquisa global, formatada, muitas vezes sem imaginação e às vezes altamente ideologizada.

Aproveitamos, portanto, da abertura mundial da pesquisa para torná-la mais colaborativa e imaginativa. Isto não exclui o rigor, pelo contrário, uma vez que obedeça a uma vigilância coletiva muito mais ampla. Abandonamos os nossos grilhões locais ou nacionais sem, no entanto, nos deixarmos levar na direção da estandardização e uniformização tendenciosamente realizadas pelos patrocinadores da pesquisa.

Continuar realizando uma pesquisa não estandartizada, multinacionalizada, parece ser hoje uma garantia de desenvolvimento e sucesso da pesquisa em ciências sociais.

\footnotetext{
i Título original no francês «La recherche en sciences sociales aujourd'hui. Conferência proferida na aula inaugural do Programa de Pós-Graduação em Educação da PUCPR, no primeiro semestre de 2014.
} 